\title{
A LOW-COST MINIATURE COUNTER SYSTEM FOR RADIOCARBON DATING
}

\author{
KAZIMIERZ JELEN* and MEBUS A GEYH
}

Niedersächsisches Landesamt für Bodenforschung D 3000) Hannover, Federal Republic of Germany

\begin{abstract}
Despite the great potential of the AMS technique for ${ }^{14} \mathrm{C}$ dating of milligram samples, the use of multiple miniature counter systems is still promising. Investment costs are relatively low and long-term financing of age determinations can be held within bounds. We have developed a ${ }^{14} \mathrm{C}$ dating system containing 10 miniature counters for $\$ 30,000$, whereas commercial systems usually cost more than $\$ 150,000$. Counting is not quite as good as that of the technically more sophisticated commercial systems, but the disadvantage for routine work is not significant. $\mathrm{CO}_{2}$ preparation and purification take less than 30 minutes of active work including measurement and data cvaluation. The cost of one age determination on a $22 \mathrm{mg}$ sample is about $\$ 35.00$
\end{abstract}

\section{INTRODUCTION}

A statistical evaluation of the weights of the submitted ${ }^{14} \mathrm{C}$ samples in 1972 showed (Geyh, 1967) that $20 \%$ contained $<150 \mathrm{mg}$ C. As a result, a ${ }^{14} \mathrm{C}$ c counter for $40 \mathrm{mg}$ samples was constructed within a plastic scintillation guard counter. However, it had three disadvantages:

1) background counting rate of $0.25 \mathrm{cpm}$ was too high,

2) memory effect was unacceptably large due to absorption of gas in the plastic scintillator, and

3) long-term stability was inadequate.

Harbottle, Sayre and Stoenner (1979) constructed quartz-tube miniature counters for small ${ }^{14} \mathrm{C}$ samples which were introduced in routine dating by (Otlet et al (1983). Despite the success of the AMS technique (Wölfli, Polach \& Andersen, 1984), the development of commercial miniature counter systems was stimulated (Kaihola et al, 1984) by vast financial savings. Miniature counter systems costing ca $\$ 150,000$ are still much less than $\$ 1,000,000$ or more for AMS accelerators. Moreover, maintainance is inexpensive and staff need not be highly skilled.

Our goal was to construct a low-cost miniature counter system with simple techniques which can also be used in Third World countries, whose interest in archacologic and ecologic research is growing rapidly.

\section{GENERAL SCHEMF}

Miniature counter systems consist of 10 to 16 low-level counters for ${ }^{14} \mathrm{C}$ dating of samples containing $10 \mathrm{to} 50 \mathrm{mg} \mathrm{C}$, a plastic or $\mathrm{NaI}(\mathrm{Tl})$ guard detector, a passive shield made of low-level lead, a filling line for the counters, and sophisticated electronics. The general scheme has been described by ()tlet $e$ al (1983). Storage and statistical evaluation of the counts, including pulse-height (PH) analysis (Otlet et al, 1983), analysis of rise-time data (RT) or time series data (TA) (Kaihola, Polach \& Kojola, 1984) is done by simple personal computers.

Carbon dioxide (Otlet et al, 1983) or methane (Kaihola et al, 1984),

* Guest scientist from the Institute of Physics and Nuclear Technology, ul Mickiewicza 30 , Pl 30018 Cracow, Poland 
which require rather complicated chemical preparation lines, are used as counting gases. Gas samples are stored in small metal or glass bottles. Measuring time is between 2 weeks and 3 months.

\section{COUNTER CONSTRUCTION ANI) FILLING SYSTEM}

The most sensitive part of the system is the low-level miniature counter and the material used in its construction must be of lowest activity. According to our experience, electrolytic copper and quartz seems to be the most promising for construction of small-volume, low-level counters for highpressure operation (Geyh, 1967). The anode is made of $25 \mu \mathrm{m}$ stainless steel (Leico Industries Inc, NY). Nylon (Polypenco, Cologne, FRG) and quartz are used for insulators. Instead of soldering, a two-component glue (UHU hart 300, FRG) was used. The construction details are shown in Figure 1. On the basis of the range of small samples that have been submitted to our laboratory, we have chosen a counter size of $15 \mathrm{ml}$ with an active length of $6 \mathrm{~cm}$ and a diameter of $1.8 \mathrm{~cm}$ filled with $\mathrm{CO}_{2}$ at $3 \mathrm{bar}$. This corresponds to samples containing $22 \mathrm{mg} \mathrm{C}$.

The first counters were made of technical-grade quartz coated with gold. High background counting rates were obtained (Table 1). Low-level gamma-spectrometric analysis showed that the technical-grade quartz was contaminated with daughter products of the uranium decay series. Quality was improved by using synthetic quartz (Suprasil from Hereaus, Hanau, FRG). The best results have been obtained with OFHC copper counters, which can be built in a day. Stuiver, Robinson and Yang (1979) found, on

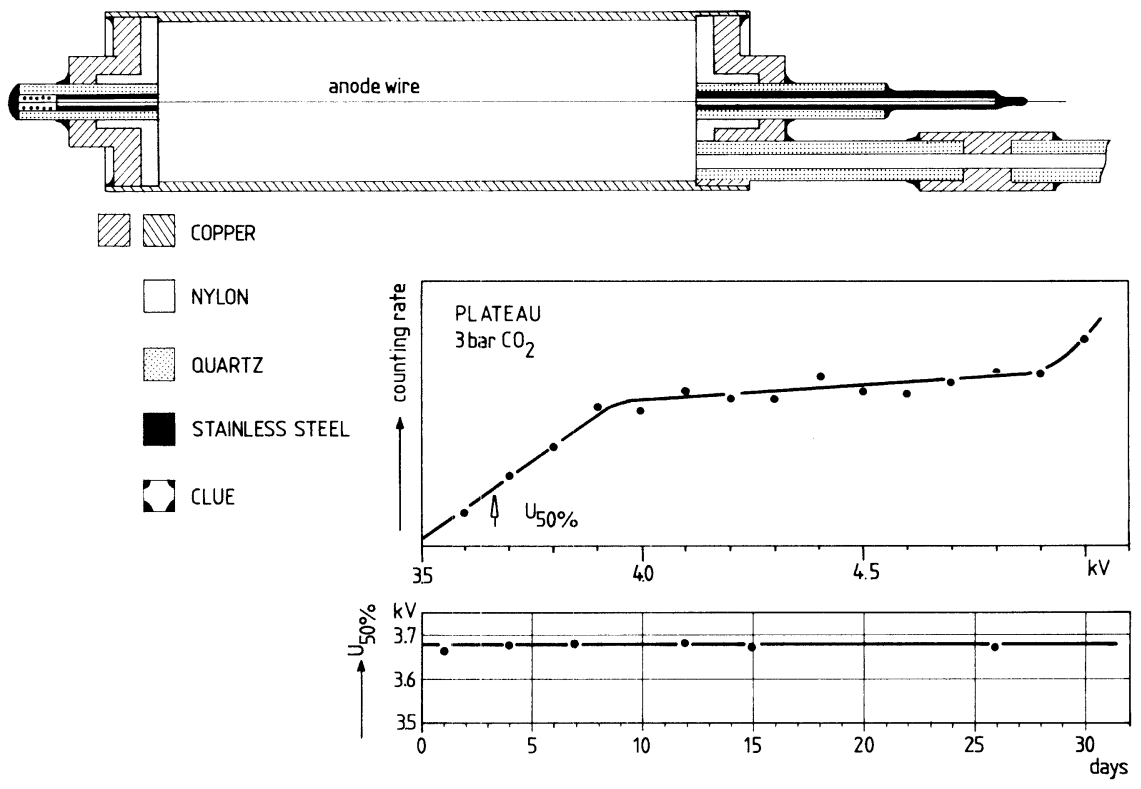

Fig 1. Scheme of the Hannover miniature counter, its plateau, and long-term constancy of the "half voltage" $\mathrm{U}_{50 \%}$ 
TABLE 1

Specifications of various types of counters

\begin{tabular}{lccccc}
\hline $\begin{array}{l}\text { Construction } \\
\text { material }\end{array}$ & $\begin{array}{c}\text { Volume } \\
(\mathrm{ml})\end{array}$ & $\begin{array}{c}\text { Pressure } \\
(\text { bar })\end{array}$ & $\begin{array}{c}\text { Quantity } \\
(\mathrm{mg} \mathrm{C})\end{array}$ & $\begin{array}{c}\text { Background } \\
(\mathrm{cpm})\end{array}$ & $\begin{array}{c}\text { Standard } \\
(\mathrm{cpm})\end{array}$ \\
\hline Techn-grade quartz & 10 & 3 & 15 & 0.18 & 0.20 \\
Suprasil quartz & 10 & 3 & 15 & 0.14 & 0.20 \\
OFHC copper & 15 & 3 & 22 & 0.04 & 0.28 \\
Otlet system & 5 & 4 & 10 & 0.02 & 0.15 \\
Kaihola system & 10 & 7.5 & 37 & 0.0625 & 0.50 \\
\hline
\end{tabular}

the contrary, that synthetic quartz has the lowest specific activity. Highpurity aluminum is being tested.

Otlet et al (1983) use separate high-voltage power supplies for each counter. Our studies show that two counters can be easily operated with one power supply if costs (Table 2) must be cut.

Results of a representative long-term test are shown in Figure 1. Using high-purity $\mathrm{CO}_{2}$ as counting gas, measurements of at least 4 weeks show no change in plateau. The anticoincidence counting rates fit Poisson statistics during this time.

Memory effect was checked with a measurement of 3 to 5 days using the Heidelberg standard (Kromer, 1984) with an activity of 10.3 times the NBS oxalic acid standard, pumping for only 2 to $3 \mathrm{hr}$, followed by four weeks of background counting. The memory effect was $<0.4 \%$. Improvement is possible by lengthening pumping time.

We use a stationary counter filling line which reduces the effective volume of the counter by 10 to $12 \%$. A counter with an effective volume of ca $92 \%$ is being constructed.

\section{SHIELDING AND GUARD COUNTER}

An inexpensive $10 \mathrm{~cm}$ shield constructed with low-level lead (Gruvaktibolag, Gotenborg, Sweden) is used. Taking into account the experience by Otlet et al (1983), common well-type $\mathrm{NaI}(\mathrm{Tl})$ scintillation detectors (HARSHAW Chemie GmbH, Wermelskirchen, FRG) are used as guard counters. But instead of large crystals, two small ones were chosen to save $80 \%$ of the costs and to be more flexible in case of defects. The most eco-

TABle 2

Costs of a dating system with 10 miniature counters $(\$ 1.00=$ ca DM 3.00)

\begin{tabular}{ll}
\hline 2 NaI(T1) well-type crystals with photomultipliers & DM 33,000 \\
1 lead shielding (10 cm thick) for two guard counters & DM 15,000 \\
10 low-level miniature counters (construction materials) & DM 2,000 \\
1 chemical preparation line made of glass, pumps, etc & DM 7,000 \\
1 filling line with 10 storage bulbs and pressure gauge & DM 6,000 \\
10 preamplifiers, amplifiers and discriminators & DM 6,000 \\
1 Commodore personal computer, disk drive, and printer & DM 5,000 \\
6 high-voltage power supplies & DM 13,500 \\
Total & DM 87,000 \\
\hline
\end{tabular}


nomic choice was a $6 \mathrm{in}^{2}$ crystal with a $6.1 \times 12 \mathrm{~cm}$ hole in an aluminum casing and a 5" photomultiplier (model EMI 97918) with magnetic shield. The crystal surrounding 4 or 6 counters has an active thickness of $4.5 \mathrm{~cm}$.

A test showed that the background counting rate $n_{0}$ is not lowered using a flat guard counter in the roof shielding (Gulliksen \& Nydal, 1979). Figure 5 shows that even lowering $n_{o}$ by $60 \%$ would not improve dating precision significantly.

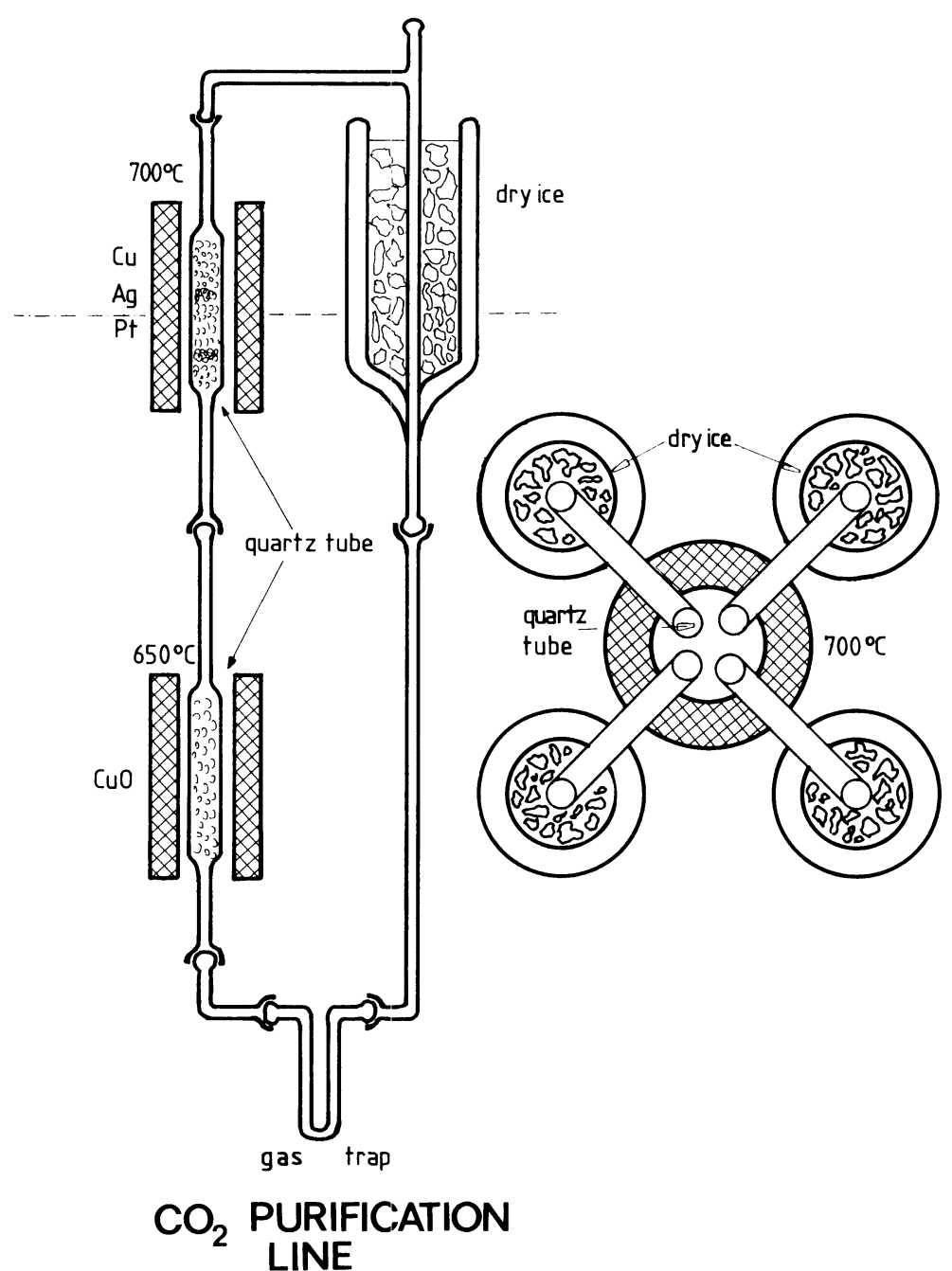

Fig 2. Scheme of the semi-automatic purification line for $\mathrm{CO}_{2}$, which is circulated through hot $\mathrm{Cu}(\mathrm{O}$ and $\mathrm{Cu}, \mathrm{Ag}$ and $\mathrm{Pt}$ for two hours; cross-section of the planned fourfold system 


\section{ELECTRONICS}

Otlet et al (1983) use separate charge pre-amplifiers, amplifiers with pulse-shaping, discriminators and peak stretching for each counter, which are connected to an analog multiplexer, ADC, and logic circuitry. The data are stored with a micro-processor. High-resolution pulse-height analysis (Otlet et $a l, 1983)$ and time-series and rise-time analysis (Kaihola, Polach \& Kojola, 1984) are recommended.

Our electronics are similar, although we use only 18 channels for each counter and 6 for routine work. We have found in routine measurements that more detailed information is needed only during test phases or the exceptional case of a counter malfunction.

\section{COUNTING GAS CHEMISTRY}

Carbon dioxide was chosen as the counting gas because the chemical preparation is simple and fast with minor contamination problems since chemicals or catalysts are not needed. A semi-automatic preparation line has been constructed (Fig 2).

High-yield oxidation of various substances such as charcoal, peat, humic acids, collagen, and wood showed that CuO does not work satisfactorily as an oxidant. Burning in a $6 \mathrm{~L}$. glass bulb filled with 0.9 bar oxygen is successful. The sample is ignited electrically in a stainless steel boat and the

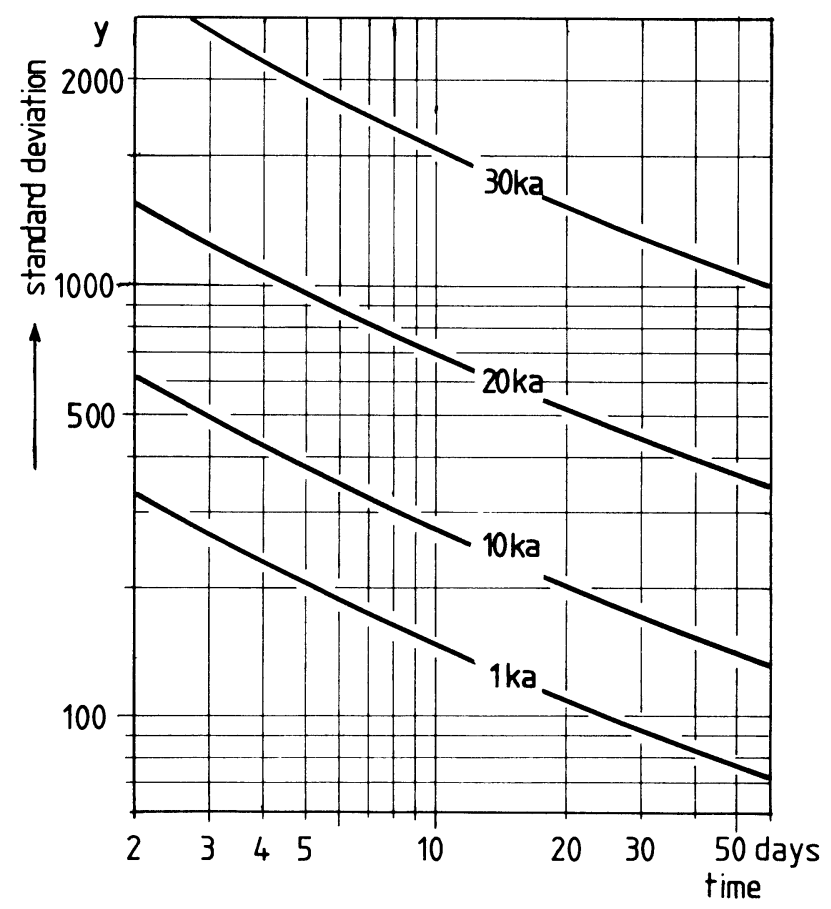

Fig 3. Increase in dating precision as a function of measuring time and the age of the sample 
$\mathrm{CO}_{2}$ is separated from the resulting gas mixture by condensation with liquid air.

For purification, $\mathrm{CO}_{2}$ (at a pressure of 0.5 to 1 bar in a $0.08 \mathrm{~L}$ convection line (Fig 2) containing a water trap) is first circulated in a tube filled with $\mathrm{CuO}$ and $\mathrm{Pt}$-asbestos at 650 to $700^{\circ} \mathrm{C}$ for two hours to oxidize any remaining hydrocarbons. $\mathrm{CuO}$ is used instead of adding oxygen to the $\mathrm{CO}_{2}$ during purification (Srdoc \& Sliepcevic, 1963) and makes it possible to semi-automatize the process. After 2 hours, the gas is circulated for 2 hours through a tube filled with $\mathrm{Cu}$ and $\mathrm{Ag}$ heated to $700^{\circ} \mathrm{C}$. In this step, nitrogen oxides are reduced to nitrogen, halogens and sulfur oxides are absorbed. No loss of $\mathrm{CO}_{2}$ occurs. A maximum of 20 min of active work is needed for the preparation of one sample.

Four purification systems will operate simultaneously and will not need any maintenance. The purity of the gas is tested by plateau measurements with a counter installed in the line. The purified $\mathrm{CO}_{2}$ is stored for one month in glass bulbs before measurement.

After more than 30 purifications, the $\mathrm{Cu}$ is regenerated with hydrogen at $6000^{\circ} \mathrm{C}$ for $15 \mathrm{~min}$.

Preliminary attempts with the $\mathrm{CaO} / \mathrm{CaCO}_{3}$ purification technique were not successful. Apparently, gaseous impurities were enclosed in the

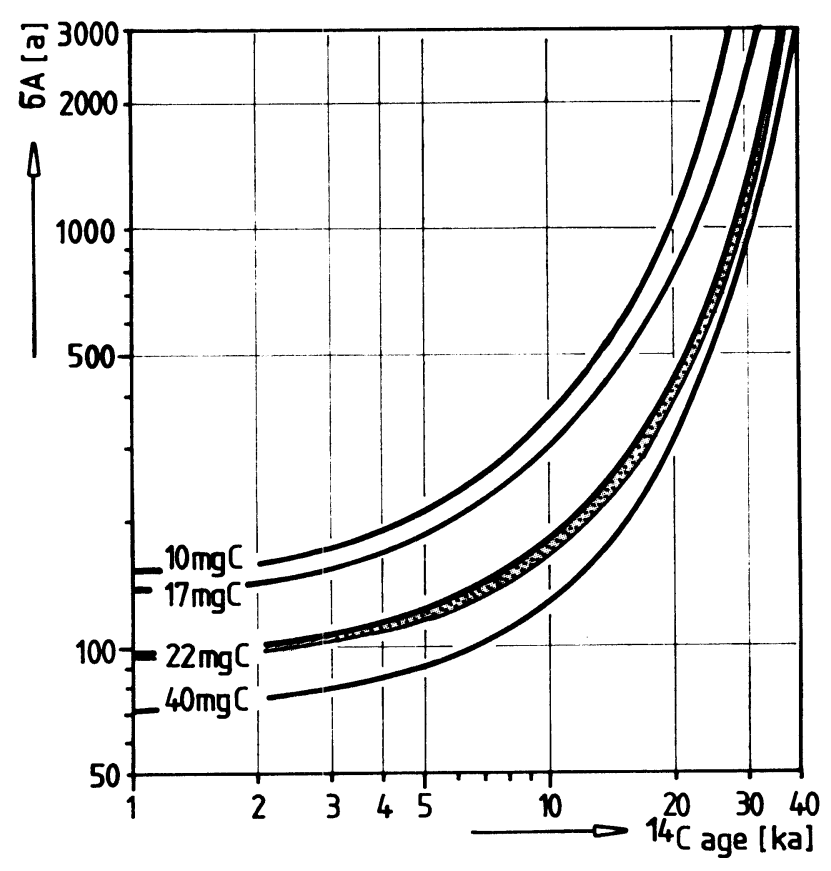

Fig 4. Dating precision of different miniature counting systems for various sample sizes. Ten and $40 \mathrm{mg}$ are used by Otlet $e t$ al (1983) and Kaihola et al (1984), respectively. Our quartz counter needs $17 \mathrm{mg} \mathrm{C}$. The copper counter is filled with $\mathrm{CO}_{2}$ of $22 \mathrm{mg} \mathrm{C}$. The dotted area shows the improvement if the background of this counter is reduced by $60 \%$. 
pores of the encrustations and therefore could not be removed by pumping.

\section{MEASUREMENTS AND STATISTICAL EVALUATION}

Ten counters are used simultaneously but independently of each other. A counting time of ca 3 weeks is usually sufficient to provide dating precision of 1 to $2 \%$ for Holocene samples (Fig 3).

Further lowering the background counting rate does not improve this figure significantly (Fig 4).

A statistical evaluation of the raw data is made every day for each counter to determine whether the sample should continue to be measured (Fig 5). This simple statistical treatment seems to be sufficient for routine work. Calculation shows how an extension of the counting time may be expected to increase dating precision. This information is useful as sample submitters usually request maximum dating accuracy without considering eco-

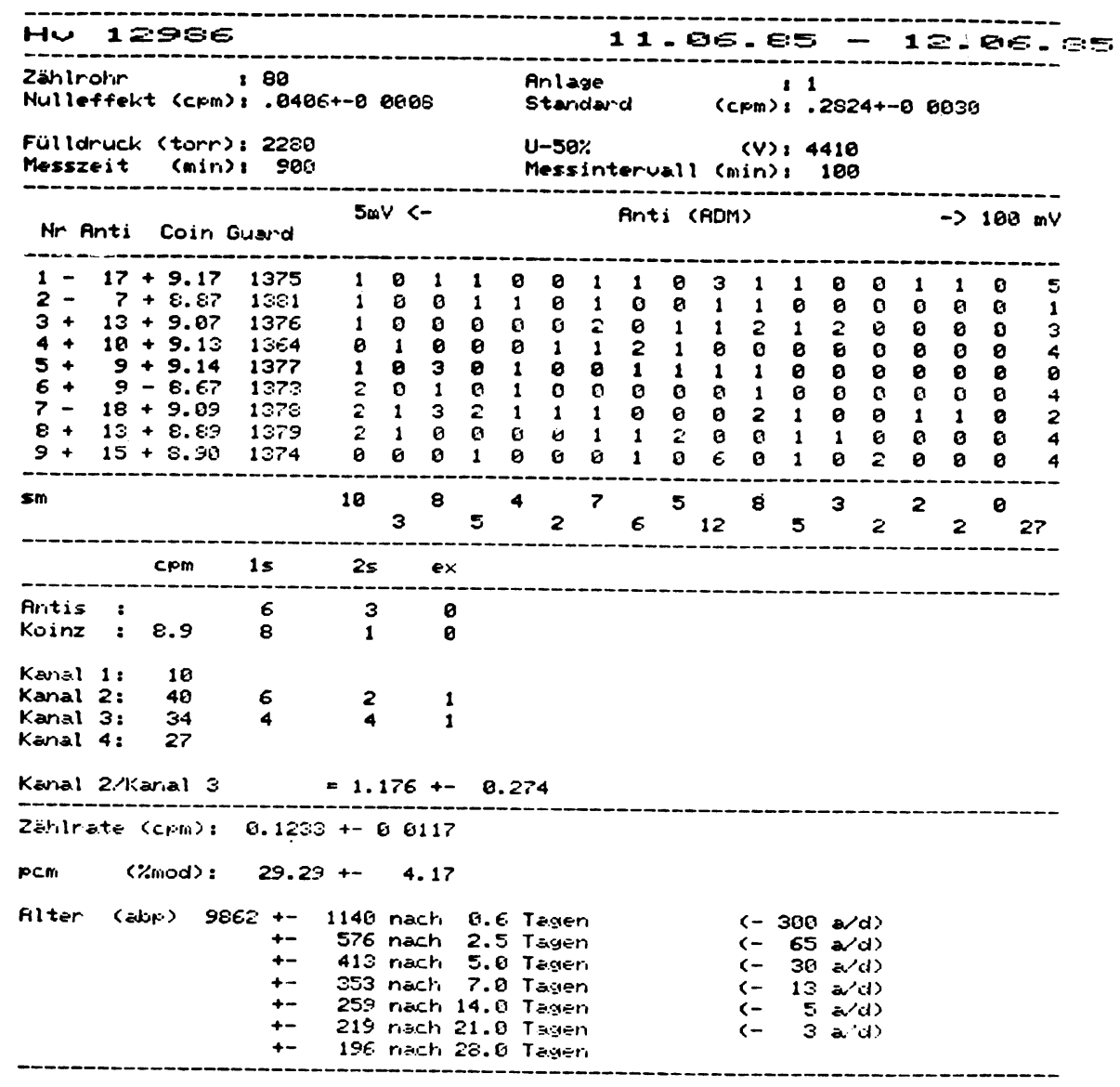

Fig 5. Printout of raw data and results of the statistical treatment for a sample 
nomic aspects. Counting time is extended only if it is shown that the standard deviation can be expected to decrease significantly.

\section{COSTS}

The costs of the system are specified in Table 2 . This system allows dating of $160-180$ samples per year, including background and standard measurements. Chemical preparation takes 20 days (DM 4000). With DM 1000 for chemicals as well as 1 M 8000 for amortization and maintenance, dating costs are ca IDM 100 per sample.

SUMMARY

A low-cost miniature counter system for ${ }^{14} \mathrm{C}$ dating of $22 \mathrm{mg}$ samples with $\mathrm{CO}_{2}$ is presented which, comparing both cost and specifications, is quite capable of competing with commercial systems (Fig 5). Costs do not exceed $\$ 30,000$ and the dating expenses are ca $\$ 35$ per sample.

\section{ACKNOWLEDGMENTS}

We thank R L. Otlet and coworkers, Harwell, R E M Hedges and R Gillespie, Oxford, for valuable information. B Kromer, Heidelberg, and G J Hennig, Hannover, gave useful comments on chemical preparation. The work of K P Hoops, Hannover, who constructed the mechanical parts of the counters, and that of $\mathrm{F}-\mathrm{W}$ Schulz, who developed the electronics, is greatly appreciated.

\section{REFERENCES}

Geyh, M A, 1967, Experience gathered in the construction of low-level counters, in Radioactive dating and methods of low-level counting: Vienna, IAEA, p 575-589.

Gulliksen, S and Nydal, R, 1979, Further improvements of counter background and shielding, in Berger, R, and Suess, $\mathrm{H}$ E, eds, Radiocarbon dating, Internatl ${ }^{14} \mathrm{C}$ conf, 9 th, Proc: Berkeley, Univ California Press, p 176-184.

Harbottle, G, Sayre, F. V and Stoenner, R W, 1979, Carbon-14 dating of small samples by proportional counting: Science, v 206, p 683-685.

Kaihola, L, Polach, $\mathrm{H}$ and Kojola, H, 1984, Time series analysis of low-level gas counting data: Radiocarbon, v 26, p 159-163.

Kaihola, I, Polach, H, Kojola, H, Tervahauta, J, Mäntynen, P and Soini, E, 1984, I.ow level gas multicounter for ${ }^{14} \mathrm{C}$ dating of small samples: Nuclear Instruments \& Methods, v 233 , p 436-438.

Kromer, B, 1984, Recalibration of Heidelberg ${ }^{14} \mathrm{C}$ laboratory data: Radiocarbon, v $26, \mathrm{p}$ 148 .

()tlet, R I, Huxtable, (;, Evans, G V, Humphreys, I) G, Short, T D and Conchie, S J, 1983, Development and operation of the Harwell small counter, in Stuiver, M and Kra, R, eds, Internatl ${ }^{14} \mathrm{C}$ conf, 11 th, Proc: Radiocarbon, v 25, no. 2, p 565-575.

Srdoc, D and Sliepcevic, A, 1963, Carbon dioxide proportional counters: effects of gaseous impurities and gas purification methods: Internatl Jour Radiation Isotopes, v 14, p 481 488

Stuiver, M, Robinson, S W and Yang, I C, $1979,{ }^{14} \mathrm{C}$ dating to 60,000 years bp with proportional counters, in Berger, $\mathrm{R}$ and Suess, $\mathrm{H}$ E, eds, Radiocarbon dating, Internatl ${ }^{14} \mathrm{C}$ conf, 9th, Proc: Berkeley, Univ California Press, p 202-215.

Wölfli, W, Polach, H A and Andersen, H H, eds, 1984, Accelerator Mass Spectrometry: Nuclear Instruments \& Methods, v 233, no. 2, 448 p. 